\title{
AL BORDE DE LA LITERARIEDAD: LITERATURA Y EPISTOLARIDAD
}

Clandio Guillén

Cuando el 11 de febrero de 1671 Madame de Sévigné escribe a su hijal adoradia, Madame de (irignan, empiezal por desempeñar el papel de madre que opina y critica, con motivo de la correspondencia de su hija. Lo gue enjuicia es la calidad de las cartas: y para ello destacia el hecho de que Madlame de Gignan escribe muy bien: "pos lettres| sont premièrement très-bien écrites». Asimismo elogia la naturalidad con que su hija consigue la aparencia de la veracidad: "elles sont premièrement tress-bien écrites; et de plus si tendres el si naturelles cu'il est impossible de ne pas les croire... Les vôtres sont vaaies el le paraissent». Así Marlame de Sévigné destacaba, aunquic fuera de paso, uno de los propósitos principales de los géneros epistolares: la apariencia de la verdad. O lo que podríamos llamar la ilusión de la no-ficcionalidad. Pero ello en segundo plano, yat (fue lo más importante, premièremént. es escribir bien. Por lo general la Marquesa busca el estilo más que el género. Style, para mayor claridad. es el término que utiliza: por ejemplo, de su propia producción dice: "vous save» que je 11 ai qu'un trait de plume; ainsi mes Iettres sont fort négligées: mais e'est mon style..." (27 de septiembre de 1671); y en otra carta cuenta que el abate Arnauld le había pedido una muestra de la escritura de Maclame de Grignan: «il me prial l'autre jour de lui montrer un morceau de votre style; son frère lui en dit du bien» (2.3 (le milyo de 1672).

Quizás fucra esta preocupación estilística una de las condiciones de la precarial literarie(lad - a mi juicio- - de la correspondencia de la ilustre escritora. Es más, me pregunto si cuando pretendemos discernir el lugar que ocupan y la calificación que merecen detemninadas cartas como literatura, o, dicho sea más téconicamente, de determinar su literariedad (digámosto con les liormalistas ruses y con todos sus seguidores), me pregunto, repito, si nos basla con descubrir que están bien escritals. 


\section{CLAUDIO GUILLÉN}

Me pregunto si de ello (lepende el problema que me va a ocupar sobre todo en las páginas siguientes, el que las cartas sean o no scan literatura. ¿Por qué las encontramos, tantas veces, aunque estén bien escritas, a orillas de la literariedad? Por otra parte, auncue la interrogación no liene nada de impertinente, no se me oculal que la cuestión se plantea o puede plantearse respecto a otros géneros, o a la literatura misma, cuyas propiedades y cualidales no se reducen al manejo del lenguaje, o no se perciben solamente a llavés de él, es decir, mediante el análisis de unos procedimientos verbales. ('Tolos conocemos a grandes, digo, a famosos escritores de hoy que han escrito admirablemente ciertas novelas (le muy mediocre calidad.)

Problema, éste, en efecto, que se enfoca mejor cuando contemplamos los métodos de la crítica literaria. En ese temeno llevo mucho tiempo pensando que el análisis microlinguiístico, quiero decir, la clase de escrutinio minucioso de contexturas verbales que practicaba la Stilislik germánica o la Fstilística española, no llegaba bastante lejos en el empeño de aprehender lo que un texto dice y lo que no dice: de sus situaciones, de sus construeciones líricas, descriptivas o narrativas, de sus valores, de sus alusiones y sugerencias, o de sus interrelaciones y efectos formales'. Amado Alonso era muy consciente de esos límites en su magistral práctica de la Fstilística. Mi propio punto de partida es, pues, pensar que el cuestionamiento de la literariedacl ha de tener muy en cuenta no sólo el tejido verbal sino el papel (le los géneros literarios. el de las formas y el de las circunstancias históricas: y que, así entendido, este cuestionamiento es muy oportuno y útil, a la hora de considerar la especificidad o peculiaridad de la escritura epistolar, vista como literatura posible.

Tampoco se me oculta que el cultivo de la coría literaria en nuestros clías es algo (omo) andar full-time por un campo sembrado de minas. Así las cosas, quienes sólo lo hacemos de tarde en tarde no podemos sino apoyamos en el buen hacer y saber de ayuellos leóricos con cuyas premisas fundamentales nos encontramos gencralmente de acuer(o. Fan Fispaña sobresale la monumental Teoría de la literantra (Madrid, 1989) de Antonio (ialréia Berrio. (jue es merecedora, dentro de los límites que ella misma se marca. de lodo nuestro respeto. Ples bien, al tratar la cuestión de la literarieclad, mediante el examen de los usos literarios del lenguaje, en lo esencial, distingue García Berrio entre dos categoríats fundamentales: la literariedad y la poeticidad. Filo recuerda hasta cierto pumto la vicja dislinción de Benedelto Croce entre poesía. como intuición de verdades, y lenterantar. como estimonio de una civilización. Pero muestro térico quiere precisar más: la literariedad es una opción; y la poeticidacl un vallor:

L.a literariedal es, según él, una opción con la que el escritor y el lector pueden comprometerse desde un principio (p. (69). La poeticidad es un valor producido por la escritura y la lectura, por medio de la intervención de ma imaginación simbólico-imaginativa (que no es meramente individual, sino ampliamente representativa, o, puede decirse, antropológica. Lat creación literaria digo yo- es sin ducla sede de la dilerencia, de la personalidad inasimilable, de la individualidad extrema. Pero ipor qué nos commueve Rimbatud tamto, por qué se relaciona con muestra propia experiencia de lo humano, enriepueciéndolat? Lats palabras del gran poela alcanzan niveles de gencralidand signilicaliva donde conluyen la individualiclad $y^{\prime}$ la universalidad lattente. Así, el texto literario es un proceso de comunicación en el que la subjetividad del lector, respaldada y justificada de tal suerte. puede elegir y vitalizar valores particulares. Si la poeticidad, es decir, si acjuella experiencia generalizalble de valores que el compromiso con la literariedad ha hecho posible, no es soilo cuestión de palabras. como es-

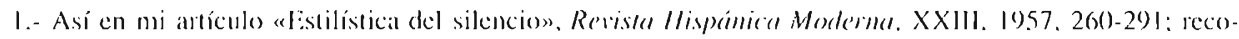
gido en mi Terorias de la hiseria line'aria. Madrid, 1989). 
cribe Carcía Berrio, qué duda cabe que de éstas arranca inicialmente: «si... se puede decir que la poeticidad no consiste en una mera 'cuestión de palabras', puede también asegurarse por el contrarios que empieza por las palabrass (p. 102).

El proceso de comunicación epistolar puede mirarse como un comimumn en cue pueden encontrarse, o locarse, o reunirse, Ires categorias principales de realización: la capacidad de lecr y escribir (litercacy; permítaseme que traduzca este término tan cómodo por «alfabetismo»); la literariedad; y la poeticidad. Veámoslo ahora así.

I

\begin{abstract}
Alfabetismo
No es la capacidad básica de leer y escribir, o literecy. o alfabetismo, solamente un réquisito o una condición para la redacción de una carta. lis un logro, una adquisición, un paso aclelante. Fin las sociedades antiguas del Mediterráneo la composición de cartas suponía sin duda un aprendizaje fundamental, un gozne esencial, que significaba un añadido, la del acto escrito tras el acto hablado. Tengo presentes aquí las palabas tan sencillas como claras de Gregory Nagy, cuando afirma: "writhen is nor something that is not orel: rather it is something in addition to being oral, and that additional something varies from society 10 society» ${ }^{2}$. I a escritura no se opone a la oralidad, ni la deja attrás, sino la supone, la implical, la contiene, suplementándola en el tránsito crucial del habla a la calla. Tan delicado sería este pasaje (que normalmente llevalaa consigo (ayer como hoy) un grado muy notable de convencionalidad. Nada más convencional, recuérdese. que una carta. Hel acceso de unos pocos a la escritura tenía que ser guiado por una estructura eficiente de normals y usos. Claro está (ue la significación del alabetismo se hallaba históricamente condicionada. Pero de todas lormas quien redactaba cartas debía hacer frente a una diferencia importante, a una índole de responsabilidikl, que dichas exigenciass convencionales le ayudaban a resolver.
\end{abstract}

Acentuaron y desarrollaron este dominio, el de un complejo de normals, las prácticas pedagógicas, convirtiéndolo en una habilidad digna de ser aprendida y enseñada. Aludo a la tradición cassi ininterrumpida de los manuales, formularios, hemelloosks, vademecums, BriefsureNer y otras publicaciones utilitarias que tanto abundaron a lo largo de los siglos: desde los tiempos helenísticos hasta, por mencionar un momento climático en la historial de la epistolatridad, mediades del siglo XVIII, cuando Samnel Richardson publica sus Leelleres Directing the

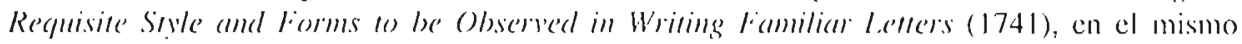
nomento al parecer en que componía Pemela, y otro novelista, (C.F. (iellent, ofrece sus Prakissche Abhandlunge'n ron dem gune'n (jeschmack in Bricfen (1751). I.os modelos epistolares que propone el manual de Richarson son más convencionales gue las cartas famosals de Pamela, pero no menos imaginados, hecho sobre el que volveré más adclante. lil autor del primer compendio helenístico cue conozcamos, Tipos epistoleres (Thipoi epistolikoí). atribuido primero a Demetrio, de fecha insegura (tal ver precristiano y revisade durante el siglo III (i.C.), ya había recomendado a un amigo 21 clases de cartas, con una breve explicación y un

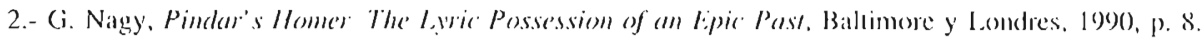




\section{(CLAIIDIC) CIUILLEN}

ejemplo para calda una: carta de recomendación, de censura, de reprensión, de consuelo. de admonición, de súplica, de apología, de felicitación. por ejemplo, o sencillamente amistosal.

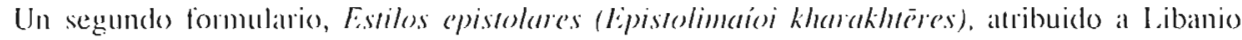
o a Proclo (del siglo IV hasla el VI d.C..). supone un desarrollo comsiderable, puesto yue propone nacla menos que 41 tipos, cada uno con su muestra apropiada?

A los cjemplos iban unidos unos brevísimos concepos. Pero es evidente que estos mamuales han sielo guias y testigos de la redacción de cartas considerada como tarea práctica. sin pretensioncs literarias, immersa en el existir cotidiano y deseosa de tener en cuenta, más que cualidades lingüísticas o retóricas, orientaciones apropiadas para las situaciones sociales y relaciones interpersonales que subyacen a loda correspondencia escrita. Aparecen como fundamentales cicrtos intereses creados, cierta especie de vinculación, de necesidacl o de dependencia, y sobre rodo cierla conciencia de clase. Lals convenciones suciales y las verbales se confuncken. En casi fodos los casos se hace hincapié no ya en el tema o estilo idóneo sino en el carácter del destinatario, su posición social y los lazos que le unen, o que podrían unirle. a quien le escribe. Sigglos después drían en aumento estos propósitos. que hacen del formulanio epistolar un libro de conesía y de conducta conecta casi un galanteo. Fillo guedará clare en los numerosos libritos que, tras la larga identificación durante la Eedad Media de la Retórica con la epistolaridal en las artes dickamimis, se producirán y distribuirán después del advenimiento de la imprenta.

Fi asunto es de sobra conocido y la bibliografía sobre él, profusa. Pero no todos destatcan que el primer mantal impreso en Furopa es el de (jaspar de Texeda, que lo presenta como ucosa nueva» cuando aparece. en 1549, en Valladolid. Tilulado Cosa murve. Primer libro de cartas mensajeras. se reedita varias veces y lo sigue en 1552 un Ségumde libro de

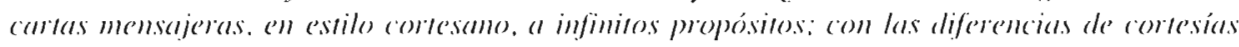
Y sohreescriphes que se usan. ¿Se vendería el librillo en las ferias de Medina del Campo y (le Villalón? I:s evidente que Iexeda, como sus sucesores (ante lodo el veneciano Francesco Sansovino, cuyo Serrenario. de 1.568, será imitado muchas vecés en fiancés, inglés y otras lenguas), procura aprovechar la oportunidad comercial que brinda el incremento de la lectura en muevas clases de hombies y mujeres. Salta a la vista lambién (pue priva la preocupación por el modo correcto de dirigirse a una persona de determinado rango social. I a terecra edición de cosa muever encierra formulas de contesía entre caballeros de igual a igual, de menos a más, y (e más a menos: hay catra-tipo de un Cardenal a su Santidacl, de un Fumbajador a un Cardenal, de un señor a un cortesino, elc. l o mismo se advierte en los sucesores españoles de Texeda, como el vi\%cáno Juan de Ycial (\%aragozal, 15.52), Juan Baptisla de Montoya (Bateza, 1.594) y Jerónimo Paolo de Manzanares, cuyo listilo y' formulario de cerras familiares (Madrid, $16(0)$ es lan pragmático (ue, según el autor, se aprenderá a escribir cartas no con preceptos sino leyendo las suyas, "lisas, llanas y sim filosofías". Que no son pocas, por cierto, sino 520. agrupadas en 28 modelos, y consagradas a temas tan poco manscendentales como "A un caballere que había pedido licencia para abrir ventana en una iglesia».

Baste acpuí con subrayar que, como bien ha nolado Víctor García de la conchat. la fic-


laes años antes que el lozarillo de Tormes. Alguno de los modelos incluidos por (iasparl de

3.- Hay extractos de estos manuales en Abraham J. Malherbe. "Ancient Lipistolary Theorists", Ohio Jemrnal of Religions Surdier. 1. 1977. 1-77.

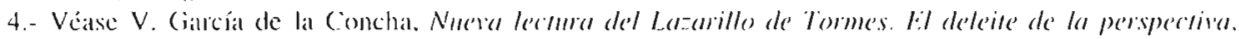
Madrid, 1979. 
Texeda es, en electo, poco menos que prenovelesco, como la carta «De un caballero mozo, preso en poder de un Rey extraño, a la mujer, estando sentencialo a degollar»; o la que empieza con estas palabras: "A Vuestra Señoría llustrísima, como a verdaclero señor, debo la cuenta de mis acciones y vida, y por eso huelgo de dalla como a mi príncipe...». Ya confluyen ahí, en potencia, la epístola y la autobiografía fingida, como luego, extratordinariamente, en el Lazarille. Valle decir (ule, por mucho que el manual epistolar se centrase generalmente en una finaliclad práctica y una rudimentaria prosia explicativa, difícil cra resistir, en sus muestras y modelos, a la tentación de la ficcionalidad; y que de tal suerte sus autores cruzatron muchas veces, desde Texeda hasta Richardson, bien que mal, la frontera de la literariedacl.

\section{Ficcionaliclad}

Si encontramos en la ficcionalidad un signo de identidal importante de la literariedad y por tanto de la poeticidacl posible, también es verdacl que no es el único; y que tampoco es imprescindible. Asimismo observamos que su aparición puede ser condicional y relativa, o seal, que existen grados y medidas de liecionalidad. Así, tratándose de la cantat, es obvio que normalmente ésta no supone una construcción fieclicio-narrativa y desde tal ángulo no aspira consciente o explícitamente a la literariedad que la novela de entradia consigue. Ahora bien. el adjetivo «ficticio» no es indivisible del sustantivo "narración». Hace un momento recordabal a Rimbaud. ¿. Y el "Bateau ivre», pongamos por calso"? ¿Son sus componentes namrativos la única condición de su fiecionalidad" ¿Qué diremos de la identidad lantástica de la voz poéticat? ¿Y del fantístico paisiaje marino, gue es como un munclo imaginardo por el poeta?

José María Pozuelo ha razonado con fuer\%a. volviendo a los argumentos de Batteux, cuue la poesía supone una indole de uimilación» (jue es hacer creativo, perecin, y concluce a la prespuesta de modelos imaginados. Fstos modeles son. también ellos, ficciones. Es más. sugiere Pozuelo gue si hay amalogía posible con las formas nambativas. la lírica se hallania cerca no del narrador personal, limitado a su propia perspectival, sino del narrador omnisciente, responsable de totaliclades s. I: poeta no se reproduce, sino se supera produciendo y dominando ámbitos y espacioss rumbo al lector. Pues bien, vayamos a nuestro tema, con algo de flexibilidid en nuestra postura.

Fin los géneros eppistolares el impulso del lenguaje y el progreso de la escritura misma han demostrado tener muchas veces consecuencias de carácter relativamente ficticio. Fis fácil (pue escribir una carta lleve al autor hacia la ficción, antes (uue hacia la literatura. No conozco mejor pruebar de la lendencial que liene el lenguaje, pase lo que pase, a somelerse a su propia lógica y su propio orden, a sufirir las consecuencias de sí mismo, y a ir edificando paulatinatmente sus propias moradas y representaciones. No hay acalso acto comparable en nuestra vida cotidiana. en cuanto a su capacidad de invención, transformación e interpretación de lo que de hecho nos acontece- o, mejor dicho, lo cyue nos acontecería si no hubiese palabras. De ahí la ambigiedad del producto — de su referencialidad a la llamada vida real ; a mitad de camino entre lo gue somos y lo caue creemos o hacemos creer gue somos.

Fi yo que escribe puede no sólo ejercer cierta influencia sobre su destinatario, como por ejemplo el Aretino cuando calsi le obliga a Miguel Ángel a enviarle unos bosquejos de sus

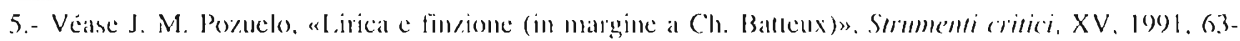
93. 


\section{CLAUDIO GUII,IEN}

frescos de la (appilla Sixtina, sino actlat lambién sobre sí mismo, sobre su propria imagen, que el Aretino en este caso modela palta (pue sea vista y estimada por el gran antista. Sammel Johnson tocó esta cuestión con su inimiable tono de vo\%, alimmando que no hay mayor tenlación de falacia y adulteración que el comercio epistolar: "there is indecel no transaction which offers stronger temptation to fallacy and sophistication that eppistolary intercourse»". lablacia, cuando la hay, que no es fácil ignorar. Lil que habla a un amigo por carla re lo que escribe, como si se encontrara sobre la marcha descubierto y desdoblado. Componer una carta. dice Pedro Salinas en su espléndido ensayo sobre el tema, "es cobrar conciencia de nosotros» . Sí. ¿pero de cuál de nosotros? ¿Li yo solicitado o estimulado por quién? No podía Salinas ignorar su propio dinamismo, su inguicude su multiplicidad. Reconorcamos así que si bien la carta no ofrece de entrada entornos envolventes y espacios alternativos. "otros mundos», sí puede desencadenar una fuersa imaginaria progresiva, parcial sin duda, pero (lecisiva y quizás irreversible; y de tal suerte ir modelando ámbitos propios. Pueden irse allirmando una voz fieticia, una imagen licticia y unos sucesos, en suma. fieticios, dentro del mundo corriente y cotidiano de los destimatarios y de los demás lectores. Percibimos una ficción dentro de lo (pue no lo es, o como dije amtes, de la ilusión de la no-ficcionalidar.

Fste élan imaginario era imparable descle un principio. Los especialistas han estudiado una carla sumeria, anterior a 1.50() a.C. dirigida a Nomna, diosa de la luna; y una epístola, encontrada en Sultantepe, ficliciamente atribuida al héroe Gilgamesh. No son escasos los cjemplos antiguos. Actoli Liman publicó, en su edición de mos papiros egipeios hallados en una tumba de Tebas, del siglo XII a.C., una colección de diez cartas literarias que elan cjercicios de escuelat, destinados a preparar a futuros escribas. En Atenas las cartas imaginarias formaron parte de la formación recórica de los alumnos desde el siglo IV a.C.. según algumos historiadotes. o tal vez después, como componentes de los ejercicios Ilamados progymmasma1a. Fil estudiante se colocaba en situaciones diferentes, o pretendía escribir como si fuera una ligura famosa del pasade, a fin de practicar varios estilos. No sorprende que esta experiencia educativa haya conducido durante el período helenístico al cultivo de la carta fingida como literattra, en manos de escritores como Alcifronte y fiilostrato. Atribuye Alcifionte (ca. 200) d.c.) sus epistolats a cuatro tipos de personas: pescadores, labradores, parásitos y prostitutas; y al situalas én un remoto momento del pasado clásico, como la Atenas de tiempos de Pericles, procura identificarse nostálgicamente con él. Les ésta la herencia que, añadicla a los saberes réóricos de los humanistas de los siglos XIV y XV, se desenvolverá y fructificará duranic el Renacimicnto.

Fi elemento de creatividad y fantasía que existe potencialmente en la escritura epistolar corriente es como una querencia que la carta ficlicia o novelesca no deberá simo libremente practicar o extender, según harán, como apreciarán tantos lectores, Richardson y Rousscau en sus narraciones extensísimas. Is este impulso lan característico de dicha clase de comunicación que la diferencia entre la carta aparentemente real y la aparentemente fingida dependerá muchas veces de pruebas y testimonios externos. Fil gue la preocupación de Séneca por su amigo y destinatario, Lacilio, sea verdatera o inventada, poco o nada liene que ver con la experiencia del lector, que no es Lucilio y no puede sino apreciar o (lesestimar la eficacia del

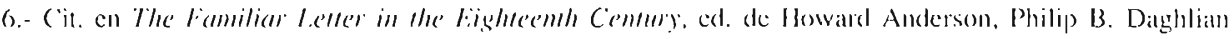
y Irwin lahrenpreis. Lawrence, Kanl., 1960, p. 2.

7.- Véase "Defensia de la carlia misiva y de la correspondencia cpisiolar", de lil Defensor. 2." ed., Matdrid. 1967. p. 29.

8.- Véase la bibliografía en mi "Notes Towatrd the Study of the Renaissance Ledterm, en Renarisame"

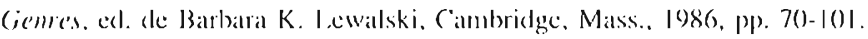


uso de la amistad y de la forma epistolar como modo de promoción de las ideals estoicas. Li lector real es el que de veras leyó y lec. alyer y hoy; no el supuesto receptor de la carta. Fin el primer Prólogo de La Noncelle Héloïse (1761). Rousseau, tan lúcido, trata de desconcertar a su lectores, al pretender inicialmente que ha reunido cartas reales, y agregar luego que es él quizís el responsable de su existencia: "ai-je fait le tout, et la correspondlance entière est-elle une fietion? (Gens du monde, que vous importe? C'est sûrement une fietion pour vous».

\section{La ilusión epistolar}

Son varias, según venimos viendo, las dimensiones de la ilusión epistolar. Sigannos un poco más lejos con el problema de la literariedad. Una reflexión lingüística como la de García Berrio tiene que habérselas con la noción tradicional del Ienguaje literario como desviación de las prácticas y restricciones de la lengua estándar o corriente. Festal noción. saltisfactoria en muchos casos, prácticos e individuales, tropiezal con dilicultades si se generaliza téricamente. Fl «lenguaje poético» es característico, pero no indispensable. Lo que sí es imprescindible en poesía es el dominio del cruce de la palabra con el tiempo, es decir, del ritmo y la forma prosódica, independientemente de la peculiantadad del léxico o) (le la sintaxis. Por Io demás Ilenri Michaux escribe en uno de sus poemas (de Éprentés, exorcismes, 1945) «Je suis l'oiseau. Tu es l'oisealu»; y sabemos que es literatura. (ierto, por otro lado, que hoy en Italia no se usa el hipérbaton en la conversación; y gue los andaluces, tan expresivos, no hablaron ni hablan como escribía (ióngora.

Fis menester tomar en consideración, pues, evidentenente, las convenciones y códigos que ordenaron y dominaron determinados sistemas históricos en períndos precisos, como contexto del surgir de un género epistolar como literatura. Fin momentos regiclos por una Poética de corte neoclásico, como el de la vejez de Torguato Tasso en Italia, o el de la madurez de Racine en Francia, la práctica del lenguaje literario es sistemática y el acto de selección léxica va unido a un complejo de normas y reglas, que puede mirarse hasta cierto punto como una diferencia, puesto yue no prevalece en el hablat o la escritura estándar. Convendría exatminar desde tal ángulo el éxito de las le'tlere volgari. distribuidas por los editores venecianos de la segunda mitad del sigglo XVI, o la práctica de Madame de Sévigné. Fin bastantes casos la redacción de una carta en prosal, y hasta de una epístola en verso, supone una desviación de la desviación; y, relativamente, una liberación del mareo semántico convencional.

Los usos linguísticos del escritor epistolar son entonces asistemáticos. Son usos que permiten disfrutar, digamos, de un grato insólito de libertad ante la lengua habladla, por un lado, y ante la literaria, por otro. es decir. las normas, las preceptivals, y ese maridaje de un solo género y un único estilo que subrayó Frich Aucrbach en su Mimesis. Y se vuelve posible, como Demetrio en Peri hermenéías (s. III a.C.), recomendar, por excepción. cl cultivo de más de un estilo en un solo escrito.

Claro que no se deben sobrevaloral las consecuencias de esta libertad repito (fue relattiva. Una epístola no es como un pocma - ni siguicra las mejores epístolas en verso. cuyo encinto reside en su proximidaal a la prosa y su poco lírico desenfade-, porefuc. sobre codo, no es probable que hallemos en ella una red comparable de relaciones verbales y formales, una densidad semejante de expresión. un nude tan apretado de enunciados polisémicos. Fillo puede ocurrir de vez en cuando, de repente, esporádicamente, como por capricho; pero si la redacción de cartas exige el alfabetismo - literacy- el peso de su litcrariedad no recac única o plenamente sobre el lenguaje. La singularidad general de la carta se manifiesta de otras 


\section{CLAUDIO (IUILLIEN}

mancras, según venimos observando. Fn el impulso imaginario que une al autor a su destinalario reside buena parte de la complejidad de la calla. La ambigüedad de las referencias al entorno cotidiano de los dos se ve superata por la borrosa identidad o la subordinación de esa segunda presencia psíquica. esal segunda persona, a quien y para (quien se escribe. De ello procede en gran parte su polisemia.

Baste con mencionar a los anores mejores y más lamosos de cantas familanes - un Plinio, un (iucvara, un Ammibale Caro, una Ladly Mary Wortley Montagu- y recordaremos esa compleja conciencia en el lecen de la multiplicidad del destinatario y por lanto det texio entero, gobernado por la superposición de la comunicación privala y la públicar. Pour qui écriton?' Claro que para el (estinatario y receptor primero, o no habría lal ambiguiedad. Y para aclararse uno mismo, como insinualsa Pedro Salinas. Pero lo que pretende ser lédo por una segunda persona principalmente es, en realidad, rekido; y relédo por otros, por otras persomas, por otras clases y grupos, a por otros públicos en dilerentes momentos históricos. De hal manera lo (que parecía mero existir privado, materia brua de vida, se convierte en literatua. Y esta utilización del otro, esla mudamza. no es sólo una contingencia o un accidente. bis algo que arranca con frecuencia de la carta misma, que no es conversación del lodo sino lambién comunicación solitaria, que ya no es habla sino escritual, susceptible de superal el elímero presente.

Fsta convergencia de lo privado y lo público no es un rasgo exclusivo de las cartals literarias. Pero en ciertos géneros epistolates desempeña un papel fundanental. Quiero decir (jue puede resultar alectadat, puesta en tela de juicio y hasta suprimida una función muy propia de la epistolaridad, (pue es la copresencia imaginada clel otro, del utú» a quien se escribe: la pertinencia del receptor. Véase por ejemplo una novela epistolar como //umphry Clinker (1771) de Smollen. Es sin duda una novela: y además. muy amena. Pero las cartas (jue la componen son poco más que un procedimiento que favorece el ejercicio de la descripción y de la nartiación por parte de una pluralidad de voces y personalidades en el momento de la acción o poeo después. Un grupo de parientes y amigos, todos galeses. más o menos excéntricos y exlravagantes, viajan por Inglanerrat y Escocia. Cata tuno escribe a un corresponsal diferente: Matnlew Bramble, que liene la obsesión (le la salud, a un amigo médico: su hermana labilla, solera en buscal de marido, a su ama de llaves; el sobrino joven y enamoradizo, Jeremy, a un compañero de clase en ()xford, ete. Pero son muy escasos los momentos ea clue cl autor de la calta, como lambién el lector externo, tiene presente la icientidad de la persona a quien se envía la descripción o el relato. Asi la epistolaridad no pasa de ser superlicial; y el destinatario es poco más que una dirección o un busón.

O limese orro ejemplo, Mademosiselle de Manpin (183.5-36), que Théophile Gautier compone cuando es un apasionado escritor novel, adherido al Romanticismo. La protagonista, D) Albert, escribe primero a un ucher ami» cuyal existencia es tolalmente nebulosal. Más adelante la persona adoracla por D’Albert y también por su amante Rosente, es decir la deliciosa Mademoiselle de Maupin, de escondida identidad sexual, se dirige a una amiga suya, llamada Craciosa, que permanece asimismo abstracta; hasta (pue por fin el narador cambia de método y habla con su prepla vo\%. Nótese que el problema, tanto en Smollell como en Gauticr, no es

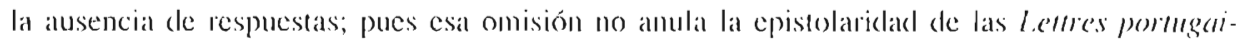
ses o de Werther. I o que sí se echa en falla es la apariencia de lazos personales, de intersubjelividad, de la importancia o relativa copresencia del tú para el yo que escribe - pertinencia que maniliesta con fiecuencia la liagmentación o la multiplicidad clel yo epistolar.

Como cjemplo de lo opuesto, cito el comienzo de unas de las carlas en prosa - magní- 


\section{AL BORDLE DLE LA LITLRARILDAD: LITLRATURA Y LPISTOLARIDAD}

ficas. y al parecer subestimadas de John Donne, mandada a su amigo Sir Thomas I.ucey. Domne caracteriza la composición y envío de ma carta como ma forma de "éxlasis". o sea un estado de unión del alma --«sialida, secesión y suspensión»-- no con Dios sino con la persona amigat:

I make account that this writing of letters, when it is with any seriousness, is a kind of ecslasy, and a deparlure and secession and suspension of the soul, which does llacn comunicate itself to two bodies: and, as I would every day provide for my soul's convoy, Hough I know not when I shall die, and perchance I shall never die, so for these ecstasies in letters. I oftentimes deliver myself over in writing when I know not when those letters shall be semt to you..."

Fista acepción del vocablo ecsurs.sy (título de un famoso poema del mismo atutor) se aproxima a la raí verbal griega, evistamai, udesplazar». y al sentido posterior (le udesplazamiento (el alma del cuerpo», como en Plotino, pero sin que se abandone el cuerpo en ningún momento. I a teoría algo juguetona de Dome supone que dos personas companten ma misma alma, sin excluir los cuerpos. Lis esto lo que un calta puede conseguir, como dice Dome al principio (le su conocida epístola en verso a Sir Ilemry Wollon (1.598):

Sir, more than kisses, letters mingle souls.

For thus friends absent speak...

John Domne, en la cama a lucey, se ha situado clatamente en el eentro demático de la tradición de la epristola familiar. No hay misterio algumo acerea de los temas principales de esta tradición, como también de lambas cartas más en su literariedad. El objecrivo principal, el interés que cubre y envuelve los (lemás, es la expresión del afécto, la amistad o el amor. La palabra es regalo (dijo Demetrio, como veremos ahora). La palabra escrita es amor, amistad, afecto. Cierto que han existido otros temas tradicionales. Pero es ése el motor u origen principal de tanta escritura epistolar, y su función más proluncla hasta tal punto que cabe perfectamente descuidar la compostura y las linezas del lenguaje. La condición de esa libertad es el sentimiento afectuoso. o su representación. Fil mensaje fundamental y constituyente es la entregil verbal, la voluntad de comunicación, la generosidad del acto mismo de expresión. la expresión misma.

\section{I a teoría epistolas}

Fis notable la preocupación de la carla comsigo misma. Acabamos de verta en Domme, que a su modo interpretaba una teoría. Comenta Barbara Johnson (con motivo de la crítica por Derrida de la lectura lacamiana de Poe) que la cartal tiende a plantearse el problemal de su situación retórica: "late letter| can be described ats that which poses the question of its own rhetorical status»" ${ }^{\prime 0}$. Fstoy de acuerdo, descle el punto de vista de mi propio planteamiento. Cuanto más se adentra el autor de cartass en la literariedad, más se preocupará y desvelará por lo que cstá haciendo. Se preguntará acerca de la caliclad y lunción de sus esluerzos. Se inquictará -como Cicerón, por cjemplo. y muchos de sus stucesores- por la conveniencia

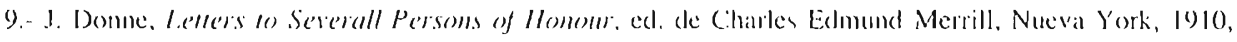
\#6, p. 10 .

10.- 13. Johnson, "The Frame of Reference: Poe, Lacan, Derricla», en Lilereny Theories in Pravis. ed. de Shirley F. Stanton, Philatelphia, 1987. p. 420. 


\section{('LAUDIO GUILLLEN}

de la materia tratada y del estilo elegido. I a carla literaria y la novela son géneros que tienen bastantes (limensiones en común: y ésta es una: la liecuencia del lenguaje metacrítico, la constante conciencia teórical.

La tradición de la teoría de la carta (tan diferente de los mamuales prácticos, menciona(los más arriba, como un libro de cocina lo es de una rellexión estructuralista sobre lo cruclo y lo cocido) se remonta a los orígenes de los géneros epistolares en Grecia y Roma. He recordado a Cicerón. que define la materia y los niveles de estilo epistolares, así como los genera epristolarum (Famm. II,4; IV,2; IX,2I. ete.). Pero el texto principal del que disponemos. muy superior a los clemás. es el epílogo al final del Peri hermeneias, o De elocurione, de Demetrio, o pseudo-Demetrio, obra a la (que un especialista, G. M. A. (irube, asigna la fecha de 27() a. ( $(.11$

Son varias las observaciones importantes de Demetrio. Me limitaré acjuí a lres, dos de las cuales aparecen juntas, con motivo de lo dicho por Artemón en un comentario suyo, hoy perdick) (\$22.3-224):

Artemón, que editó las cartas de Aristóteles, diece que las carlas y los diálogos deben escribirse del mismo modo, pues una carta es como uno de los dos lados de an diálogo. $A \mathrm{ggo}$ de razón tiene en lo (pue dice. pero no es todo. La carta debe escribirse con algo más (le esmero que un diálogo. Fi diálogo imila una conversación improvisaldat, pero la calla es una forma de escritura y se envía a alguien a modo de regalo

Destacó Demerrio lo esencial: la comunicación epistolar se efectúa por medio de la escritura - ess cscritura - y como tal no puede considerarse, a diferencia del diálogo, como la imitación de un intercambio hablado, como habla, o como simulacro (le habla. Li intercambio de réplicas escritas no significa (jue la carta misma reproduce un diálogo parcial o completamente, excepto cuando lo cita. Pero el deseo de ese encuentro habladlo inexistente, la nostalgia de esa conversación real que no hay, sí coincide con la expresión de la amistad y el envío de la carla "a modo de regalo». Más adelante, en efecto, Demetrio, que se encuentra probablemente en la estela de la evaluación aristotélica de la amistad, subraya esta circumslancial (\#232):

I.a bellèa de una carta reside en la expresión de afecto y cortesía, y también en el uso frecuente de sentencias vicjas y proverbios. Es ésla la única sabiduría que una carla clebiera contener, ya (pue si el escritor desarrolla reflexiones generales y exige cierta forma de vida, no está conversando con un amigo por medio de una carta, antes bien le está predicando.

La terecra reflexión es, pues. negativa. Una carta no lebe ser filosofía, ni adoctrinamiento, ni predicación. "Lil que explica Lógica -agrega Demetrio o Ciencia Natural en una carta sin (luda escribe, pero no está escribiendo una calla) (\#2.31). Incluso insinúa (puc las cartas de Platón y Tucílicles son, lancamente, un latazo. Fste distanciamiento frente a la fïlosolía seguirá siendo fundamental en la tradición de la carta familiar. Muchos textos teóricos lo recalcan, y bastantes autores de paso en sus cartas. Arefúmedes, Séneca en sus momentos más didácticos, los Apóstoles, los Padres de la Iglesia, los autores de "cartas fïlológicass», los ensalyistas de la llustración, o Schiller en sus escritos sobre Fostética, sabrían perfectamente cuándo rebasaban, en sus epístolas, los límites de la autenticidad epistolar.

Pese a la matización de Demenrio, la idea de Artemón se convintió en el hopos más fie-

II.- Véase (i. M. A. Cirube, A Cirech Critic. Demerrins on Stỵle, Toronte, 1961. 
cuente y repetide en el itinerario de las definiciones teóricás de la epistolaridad. Aspira Séneca a que su carta sea qualis sermo. como una conversación o una charla (Epist. 75). Aclara San Ambrosio a su amigo Sabino que los amigos separados disfrutan así de la conversación como si estuvieran cerca, «inter absentes praesentium sermo est.» (Fipist. 49). Repite Frasmo en su tratado teórico, muy lé́lo en su épocal, De conscribendis eppistolis (1.522): «epistola absentium amicorum quasi mutuus scrmo». En su propio tatado, de idéntico título, de 15.34, Juan Luis Vives prescinde del quasi: «epistola est sermo absentium per litteras». Y el tópico sobrevive, (lescle luego, en los manuales prácticos, intelectualmente rudimentarios, como el de Angel Day en Inglaterra («the familiar and mutuall talk of one absent friend to another» $|1595|$ ), el de P. (). de Vaumorière («un écrit envoyé à une personne absente pour lui faire savoir ce que nous lui dirions si nous étions en étal de lui parters |1595|) y el de C. F. (icIlert ("der Brief|... die Stelle cines Gespriachs vertritt» [175]|) '2.

No sé si la persistencia de este concepto se debe al hecho de que el habla es la condición y circunstancia de la escritura; o a la rutina pedagógica; o a una ilusión epistolar más. Pero conste que los téoricos mejores evolucionaron al respecto, a partir del Renacimiento, o más concretamente, desde mediados (jel siglo XVI, que vio lat primera gran oleada de epistolariclad en la historia de las nodemas literaturas curopeas. Un momento decisivo fue la aparición de la De epistolica institutio de Justo Lipsio, en 1570. El gran humanista flanenco publicó en apéndice el érurrsus de Demetrio, en griego y latín; y su propia definición de la carti elude cuidadosamente cl tópico: «scriptum animi nuntium ad absentes, aut cuasi absentes. 1.3.

Aun así, un epistológrafo an refinado como Lord Chesterlield puclo escribir a su hijo lo siguiente, a mediados del siglo XVIII: "letters should be easy and natural, and convey to persons 10 whom we send them, just what we would say to those persons, if we were with them»". ¿'Transmitir a una persona lo que le diriámos si estuviéramos con ella? Curiosamente, quien no suscribiría estas ideas es el novelista que incluye cartas en sus matraciones por el motivo opuesto, es decir, con objeto de suplir lo que sus personajes no osinn o no pueden decirse de viva vor. Por ejemplo Balzace, en Lee lays dans la vallée (18.35-1836).

Lecmos en esa novela la historia del anor fidelísimo del héroe, lélix, por la Condesal de Mortsauf, a cuicon adora y venera durante largos años sin atreverse a pedir ninguna intimidacd real. Pero poco antes de morir la Condesa dirige una larga epístola a l’élix en cfue confiesa que le ha deseado como mujer (lescle sicmpre. Por lin la Condesa le cscribe, in articulo mortis. lo gue nunca le diría si estuvieran juntos - dicho seal con términos de Lord Chesterfield; y lo cue jamás le dijo cuando estuvo con él.

Volviendo hacia atrís, el locues classicus está en Ovidio, las Me'lamorfosis, libro) IX (v. 454-60.5). Byblis lucha contra la pasión ilícita que siente por su hermano, hasta cue por fin cede y decide confesarle su «secreto amor» en una carta privada (cuya atomentada redacción Ovidio (lescribe con (letalle). Hi hermano rechaza la propuesta y se marcha indignado. Entonces Byblis, desesperada, lamenta amargamente el haberle escrito, en ve\% de haberle descubierto sus sentimientos caral a cara.

12.- Véase mi «Notes Toward the Study...». p. 77.

13.- Lipsius. Opera ommia. Bruselas, 1570, II, p. 1.068.

14.- Cit. en William Henty Irving, The Provideme of Wit in the Einglish Lenter Writers, Nueva York, 1975 , р. 22.5. 


\section{(I.AUIDIO) GUILLÉN}

\section{I cos géneros}

Hay una norma que hallamos en casi todos los escritos dedicados a la teoría cpistolar: la necesidad de brevitas. Va unida generalmente esta exigencia a la le claridad, perspricuitas. aunque esta segunda recomendación causa dificultades: es relativa a la competencia del lector, como dice brasmo lo que es oscuro para uno, para otro es claro ( "cpuod huic obscurum est. illi dilucidum»)—: y' sobre todo puede haber conflicto entre las dos cualidades, no sienclo fácil ser breve y claro al mismo tiempo. Afirma Ben Jonson al principio de una de sus epístolas en verso, "lo Master John Selden» (1614), su intención de conciliar las dos:

I know to whom I write. Here, I am sure,

Though I am short, I camnol be obscure.

Interesa esta brevitas porque no significa solamente una ecomomía verbal y un aspecto del estilo. Se tratla también del conjunto de un relato (una de las rirtures marrarionis según Cicerón y Quintiliano) o de una mediación. de la selección de un tema, del perfil de una idea. Nos ubliga ante todo a tener en cuenta cue la carta, auncue no se encuentre circunscrita y sujeta como un soneto, no callece de límites. Digamos más bien que se limita a sí misma. Es imprevisible pero necesaria una deteminación formal. Hel escritor epistolar, a diferencia de otros, no se encontrará desde un principio ante un uespacio textual cerrado» - como dice García Berrio's, pero sus decisiones harán que larde o temprano el papel ulilizado --o pergamino, elc.-- sea una especie (le marco.

Es más, la elección del formato epistolar supondrá también la del conjumto en que se coloca la carta singular, es decir, del libo, en los dos casos que mencionaré más aldelante: la colección de cartas familiares; y la novela cpistolar. Vale decir que esta clase de decisión formal implica un compromiso eon cierto género literario. Ahora bien. no se me oculal (jue abordo ahora un terreno resbaladizo. Y se me preguntarí que a qué clases de géneros me refïero.

Mi aproximación es histótica, descle luego, y no se trata de clasificar. No aludo a laxinomías nuestras, en primela instancia. ni a parecidos de limmilia, sino a los modelos ol reciclos por los sistemas de comvenciones de determinados momentos pretéritos a la lensión entre la poesía, o la literatura, y la Poérica. Fa género literario ha side la zona de combate in illo tempore. el lugar de selección, aprendizaje. rechazo y encuenter ente el escritor y los paradigmas encarnalos en obras y attores stuperiores y momaltivos- (le un sistema histónico singular. De ahí arranca la opeción (que, como explicala (iarcía Berrio, antuncia la literariedald.

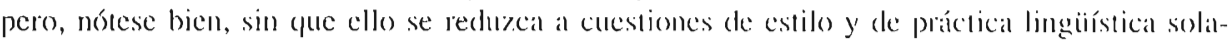
mente.

Fil libérrimo escritor de caltas elige un género, lo cual trae consigo dos consecuencias importantes: que disminuye sensiblemente su liberlad: y gue con esta decisión ingresal en lat literariedacl. Pero la selección del género se sitúa y entiende en el contexto (le un tiempo preciso y de ma sociedad decminada: es utime-specific» y "culture-specific», dice Thomas Greene th. Claro yue esta insistencia de Giecne y mía en el género no es el punto de vista de bastantes teóricos en este campo, por ahora, matándose de literariedad, como (iérard Gienelte,

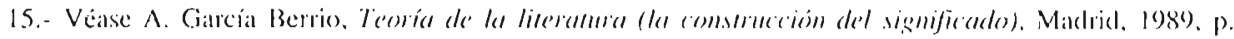
79.

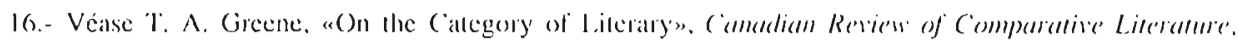
XIII. $1986,219$. 
segúm veremos luego. Fis evidente, de lodas formas, que una teoría de la literariedad no puede prescinclir de una teoría de los géneros.

Admitamos cue la epistolaridad es un cauce de comunicación radical tan radical, o casi, como la narración o la representación dramálica ${ }^{12}$. Y destaquemos los tres géneros principales que este cance de hecho ha originado durante varios siglos de literatura europea, a saber, la cartil familiar, la epístola en verso y la novela epistolar. Fin cada uno de estos tres casos me reducité al un momento o dos que tengo por decisivos, o representativos, de la plasmación y desarrollo de los géneros que nos ennciernen: y comentaré las condiciones de la literariedad de cada uno.

\subsection{5}

Durante el mes de mayo de 1.345 descubre Petratca en Verona manuscritos de las cartas de Cicerón ad Anicum. ad Brutum y ud Quinnum fratrem. Cicrto es que se habían conocido desde la Antigiiedad el talento y el talante epistolares de Cicerón, y coue los estudiosos de la Fidad Media tuvieron acceso a algunals de las cartas. Lo probable. sin embargo, es (jue no las entendieran muy bien's. Pero, por supuesto, Petrarca sí. Tampoco sería este descubrimiento el camino de Damasco para él, pues desde su primera juventud se había sentido extraño a la identificación, entonecs predominante, de los saberes retórices con la epistolaridad. Pero patsará a concebir. hacia 13.50, el proyecto de hacer de la colección de sus propias cartas latinas la tarea (le tocla una viela, comparable, hasta cierto punto, a la reunión de sus sonetos amorosos y otras poesials toscanas en un solo ciclo y un soto volumen.

Pelrarca se dedical entonces a estudiar el arte de sus predecesores, no reduciéndose a Cicerón; considera cuál debe ser el número de libros en que conviene dividlir la totalidad ¿ (Boce como la lincida?? ¿veintidós como las epístolas de Sénecia?; y hasta llega a encomendar la revisión de partes de su correspondencia a unos amigos. Petrarca vacila y se incluicta; corrige las piezas más juveniles; se preocupa acerca del equilibrio eleseable de páginas con los diferentes libros y momentos de su vida, añadiendo algunas cartas a las de la juventud; elimina o destruye muchas; y sigue escribiendo otras nuevas, desde luego, pero guiado ahora por el proyecto global. Su libro de poemas en lengua vernácula tendrá 366 unidades. Fiscribe al joven Boccaccio que espera juntar 3.50) epístolas en prosil, que acabará dividienclo por fin en los 24 -como Homero- libros de las fomiliares (Rermm familiarmm libri): a las que agregará dos secciones: Sine nomine y Seniles. Se someten las dos primeras partes a revisión, pero la muerte impiede corregir las Seniless (Rerum senilium libri), que sumarám 127 unidades.

No tiene nada de extraordinario el que Petrarca revisara, reescribiera y dispusicra su corespondencial, con objeto de prepararla para la publicación. Li propio Cicerón había empren-

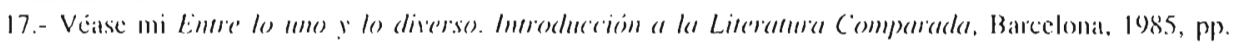
$141-181$.

18. Véasc D. R. Shatckleson Bailey, Introducción a Cicuro's lenters to Anicus. Cambridge, 1965, I, p. 6.5 . 


\section{CLAUDIO GIJILLIEN}

dido esa tarea poco antes de su muerte; y el proyecto o deseo de eventual aparición a la luz. del día, con la amalgama de privacidad y publicidad que ello implica, será las más de las veces una propiedad fundamental, aunque no siempre visible, de las lenere volgari ilalianas del siglo XVI, de los éprisoliers franceses del siglo XVII, le sus sucesores ingleses, y en general. podría decirse, de la epístola llamada familiar. Ahora bien, lo exeepcional en el caso de Petrarca es la organicidad de la racoolar, la determinación de estructurar y congregar lodas las epístolas en un gran libro único.

La analogía con la disposición cambiante de las Rime spense - del cancionero en lengua loscana - es muy significativa. Se piensa que Petrarca permitió que circulase una primera versión en 1359 (el manuscrio Chigi L.V. 176 del Vaticano), que consta de 215 pocmas. Ilacia 1366 se agregan más poemas y se revisa el orden del conjunto. Trabajo, éste, de corrección y estructuración que continuó hasta los últimos años de la vida del pocta, cuando vuelve a numerar los treinta poemas finales. La disposición delinitiva es en apariencia cronológica, presentándose como una forma de relato, como una Vita mover sin prosa narrativa; y hasta cierto punto lo sería. Pero cono ha aclarado muy bien Robert Durling, el sentido más intimo y hondo de cada poema se manifiesta plenamente más tarde, en un punto posterior del transcurso del tiempo, que es (lispersión y también voluntad de recuperación e integración, por parte (lel poetal, de los momentos vividos sucesivamente ${ }^{14}$.

I a epístola singular, asimismo, no es sino un fragmento, indivisible de un segmento muy breve de tiempo, fugaz y clemasiado próximo, demasiado pegado a la existencia mismal, como para ser plenamente comprensible. I a significación ha de buscarse en el proceso entero, en el itincrario simuoso de una conciencia moral particular que se esfucra y lucha duranle inda una vicla, poniendo a prueba poco a poco lo gue creía cue sabía, y modelándose a sí misma de año en año y de día en clía. El lector del conjunto encuentra así una tensión totalizadora entre la búscueda de un modelo o un sentido unitario y las diferencias (fue fragmenlan y las experiencias que modifican, con tan lúcida consciencia de la temporalidad, en Petratea, y de la indiviclualidad modificadora.

¿Cuál es la raíz de la literariedad? Fn este caso la opción comstiluyente está clala, aunque no todas las teorías actuales le den fácil entrada. Es la decisión de reunir un libro o conjumto estructurado de epístolas. Un libro, como los poéticos de I Ioracio, Virgilio, Propercio u Ovidio, pero de prosas epistolares. Se trata de una cualidad formal o estructural, en un sentido no exclusivamente verbal o microlinguístico de estos adjetivos. Cualidad, ésta, que señala que la obra es literatura. Y esta condición es independiente de los valores procedentes de una cvaluación estética, por ejemplo, ante la calidad de la prosa latina de Petrarea.

\section{4}

Decía Whitchead que la historia de la filosofía es una nota a pie (le página, una foomo1e. puesta al pensamiento de Platón. Pasindo ahora a la epístola en verso, no sería del todo descabellado reconocer que es una nota relativa a la poesía de Horacio. Recordemos el día en que Garcilaso de la Vega escribe la primera epístola horaciana en español. Es el I2 de oclubie de 15.34. (Fil final del poema da el mes y el día, práctica que se convierte en una de las

19.- Véase R. M. Durling, Introducción a Perrarthis l,yric Poems, Cambridge, Mass., 1976, p. 10. Y so-

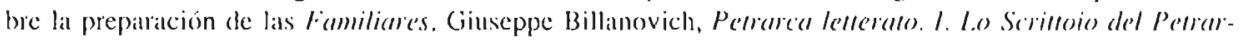
ca, Roma, 1947. 
convenciones del género.) No se había olvidado la Edad Media de IIoracio y Petrarca había compuesto sus lepistole métricas en latín. Pero es la generación de Garcilaso, Clément Marot y Sir Thomas Wyatl la que comienza a cultivar los principales géneros antiguos en las lenguas vulgares.

Recordaré el principio de la epístola a Boscán, que nos interesa apuí por dos motivos, entrelazados en estos primeros versos - las alusiones a la teoría epistolar; y, conjuntamente, a la prioridad de la amistad:

Señor Boscán, (puien tanto gusto tiene de daros cuenta de los pensamientos, hasta las cosas que no tienen nombre, no le podrá fallar con vos materia, ni será menester buscar estilo presto, distinto, d'ornamento puro, tal cual a culta epístola conviene.

Desde un principio se maniliesta una conciencia teórica. Garcilaso alude a dos de las cuestiones planteadas por la teoría de la carta, la selección de una "materia» idónea (como por ejemplo en Cicerón. y desde luego los téóricos griegos) y la de un «estilo» propio del género, es decir, dotado de brevitas ("presto»), perspicuitas («distinto») y sencille\% exenla de adornos — "lal cual a culta epístola conviene». Alora bien, i,por qué se ofrecen sin difícultacl estas cualielades? Porque son éstas precisannente las virtudes de la amistad que tiene el pocta con el destinatario:

Entre muy grandes bienes gue consigo

el amistad perfeta nos concede es aqueste descuido suclto y puro,

lejos de las curiosa pesallumbre.

Es decir, el ejercicio de la escritura epistolar es como la amistad, se parece a la amistad, consintiendo una excepcional ausencia de contapisas y ceremonias, de atención diligente a normas convencionales - permitiendo el uso, en una palabra, de la libertad.

Y no sigo. Mucho más habría que decir sobre este «lescuido suelto y puro», pero creo que, en el contexto del presente ensayo, lo escrito por Giarcilaso está bastante claro. Recuérdese sólo que acto seguido el poeta, tras esta introducción,

y así, de aquesta libertad go\%ando,

declicará el resto del poema al viaje de doce días que acabal de realizar, a caballo, rumbo a Nápoles. entre Barcelona y Aviñón. Lo que hará es dar cuenta de los pensamientos a los que dio rienda suelta durante el viaje a caballo, (jue fueron una meditación sobre la naturalezat de la amistad. Fista meditación. procedente al parecer del libro VIII de la litica Nicoméiquéa de Aristóteles, ocupa la mayor parte del poema, unos 38 versos.

Si el propósito de Garcilaso es infundir vida nueva en un género antiguo, su lucider es asombrosa. Pues la epístola moral horaciana se apoyaba fundamentalmente en las circunstancias de la amistad. Sólo ésta hacía que la expresión de preceptos y consejos morales fuera aceptable. Un amigo escribía a otro, muy particular e individualmente. Es este marco, csta circunstancia envolvente, lo que hace posible en Horacio que unas ideals abstractas - - cierta «filosolía moral»- adquieran un carácter o una pertinencia existencial, móvil, temporal. 


\section{CLAUUDI) (GUII.I.ÉN}

Ln Horacio el hombre asume la complejidad de la vida, gue es una sucesión de perplejidades, y convierte su experiencia en un proceso. Son varials las actiludes morales posibles (pocos años antes de la era cristiana), pero uno dispone sólo de una vida. Fxistir es elegir y decidir entre opciones y alternativas. La vida es un devenir y el homberes perlectible. Fsiso es lo (que el poeta puede no ya cnseñar sino compartir, o ir compartiendo sobre la marchal. a lo largo de un común camino, con el amigo a quien escribe. La epístolat. centrada en la amislacl. alproxima assi la élica al vivir.

Tanto es así que (árcilaso, como perfecto conocedor del modelo. convierte la amistad no ya en el mareo sino en el tema principal de la epístola a Boscán, mientras al mismo tiempo atribuye a la forma del poema una cle las cualidades de la amistacl, que es la informalidad. Festa libertad frente a las nomas, "lejos de la curiosa pesadumbre», pasará a ser poco menos que una nueva norma y un nuevo valor que permita descubrir. a través de la gran ola de epistolaridad que cubre a Furopa durante el Renacimiento, la poeticidad posible de la carrla.

I o propio (de. la epístola en verso (a diferencia de cualcuier poemal dirigido o dedicaklo a alguien) es que se maniliesta y presenta a sí misma como escritura, como corresponelencia escrita (por ejemplo, indicando la fechas en (jue se redacta), y en este sentido no es poesía lírica, no es hija o sucesora del canto o de la canción. Así, ningún poema de (iarcilaso se aleja tanto del Cancionero de Petrarca. Por otro lado, el género opta por el verso y no pretende. ni puede pretender, liberarse de las convenciones de la litcrattra del mismo modo o en el mismo grado que la epístola familiar en prosa.

Vista así, la epístola holaciana se sitúa radicalmente en la literariedacl. Pero creo que ésta es significativa sobre todo si se sopesa la función del género, más que el carácter del lenguaje como poesía. Ciarcilaso recihe, interpreta y perpetúa el género horaciano. Si insistiéramos en cue la literariedad procede de las cualidades formales de la poesía, no percibiríamos bien la especificidad de la epístola en verso, que estriba en los límites asignados a estas cualidades, bordeando la prosa discursiva y la lïlosofía moral. Lil valor poćlico de la epístola reside en su proximidad a la prosa. A este riesgo se deben los logros de Garcilaso, Marot. A.lclana, Donne o Ben Jonson; así como la mediocridad — siendo ańn literatura, o presendiendo serlo- de no pocals epístolas del siglo XVIII.

Ires años más tarde. el 29) de diciembre de 15.37, los primeros ejemplares del volumen incial de las cartas de Pietro Aretino salen de la imprenta de Franceseo Marcolini en Venecia. El éxilo es fulminante. De enero de 1.538 a febrero de 1.539 el libro se reimprimirá dies. veces. Aretino, que no tiene entonces más que 44 años, publicalá cuatro volúmenes más durante su vida, hasta 1555; y un sexto aparecerá, póstumo, en 15.55.

Fue Aretino el primer escritor en la historia de la literatura enropea que publicó él mismo sus propias cartas privadas. más de tres mil, escritas en lengua vernácula, mientras vivía, es más, muchas veces micntras las estaba escribiendo, sin pararse a preparar y ordenar, como Petrarca, una colección lutura. Sus corresponsales se encontraban ante la inminencia consiante de ver sus nombres y asuntos en letras de molde. Intre la tentación de la fama y el peligro de la difamación, observaban cómo la publicación ininterrumpida de esta correspondencia conseguŕa para su autor cuotas extraordinarias de poder. Arectino sabía perfectamente adular, 
pedir. manipular, seducir, amenazar y, en suma, hacer lo (jue le dabal la gana. Fra muy dueño de conducirse como se le antojaba -hasta, en no pocas ocasiones, de portarse con delicadeLa y generosidad.

Descle su primera juventud Aretino había procuraclo ridiculizar las instituciones establecidas de la literatura, mientras al mismo tiempo las utilizalat. El éxito popular de sus volúmenes de cartas supuestamente privadas - -imitadias inmediatamente por inmumerables sucesores en Venecia-.- pudo contribuir de modo decisivo al cuestionamiento y llexibilización de la Poética tradicional, por un lado, pero también, por otro, a la introducción de la epistolaridad en los espacios cada ve\% más amplios de la literatura del siglo XVI, en franca evolución y renovación. La ilusión epistolar es ahora la de una ausencia de deliberación claro está que muy deliberalla. Aretino se cuida mucho de producir una impresión de espontancidad, de improvisación (como en cierla músical de ạuclli época), mientras reduce cada carta a un solo asunto. con total dominio del texto, en la tradición monotemática de la epístola familiar. Fn el debate entre Arte y Naturalčal, tan callacterístico de la épocal, mantiene Aretino que la poesía es «un capricho de la naturaleza en sus alegrías» - «un ghiribizzo (lella natura nelle sue allegrezze», explical en carta del 5 de junio de 1537 a Lodovico Dolec (col la primera edición, a Niccolo Franco, con quien Aretino luego se enfadó a muerte), pero no sin demostrar una y otra ves su conocimiento del olicio literario, por cjemplo en sus sonetos obscenos, que llevan rime identiche y estrambotes, a la manera del entonces famoso pocta Serafino Acpuilano. «Sappiate» —escribe el 6 de agosto de 1.537 a Antonio (iallo uche la natura senza la esercitazione è un seme chiuso nel cartaccio; c l'arte senza lei c̀ niente» 20.

La relación entre erotismo y escritura epistolar es evidentemente significativat. Hacia 1524, cuando aun vivía en Roma, Aretino había agregado dieciséis sonetos a los Modi dibujaclos por Giulio Romano y grabades por Marcantonio Raimondi. Pero los poemas no son meras ilustraciones o descripciones de las posiciones amorosas. Son, casi todós, diálogos. en gue los amantes se expresan libremente, sin trabas ni tabúes verbales de ninguna clase, en el mismo momento del acto sexual. Los amantes no sólo hacen sino dicen, dando vor a todo cuanto en el (teseo es conciencia e inteligencia"'. Lo importante acpuí, para nosotros, es to que la cartal y la poesía erótica tienen en común: la voluntad de publicar. o seal, de hacer públicas, la experiencia y expresión de las relaciones más privadlas.

Aclviértase que Aretino no distingue entre ante literario y epistolariclad. Se asigna a los des el mismo elesignio de espontancidad natural. No así sus sucesores de fines del siglo XVII y sigfo XVIII (donde al modelo italiano y al francés, sobre todo a Mme. de Sévigné, se añade la memoria de los paradigmas latinos, como Cicerón, Sénecal y Plinio), que hacen hincitpié en esa misma cualidad como condición específicamente epistolar. Sivift escribe sus cartals, dice, sin interrupción ni vacilación alguna: "when I sit down to write a letter, I never lean upon my elbow, till I have finished it». Y Sterne hace gala de despreciar a quicnes incluyen en una carta una sola palabra calculatla, «one premeditated word»; pues «such an intercourse would be an abomination; and I would as soon go and commit fornication wih the Moabites, as have a hand in anything of this kind, unless written in that careless irregularity ol a gool and an easy hcart»".

20.- Cito la edición de Time le opere de Pietro Aletino por Francesco Flora y Alessandro del Vila, Mondactori, 1900.

21.- Véase / Modi, de Pietro Aretino, Marcantonio Raimondi y Giulio Romano, ed. de I.ynne Latwner. Evanston, III, I988.

22.- (it. en The Familian letter..., pp. 14, 130. 
Luego volveré sobre esta éstética de la maturalidad y del (lescuido, com motivo de la novela epistolar. Primero nos toca interrogar la literariedad de la epístola familiar en prosal. No es problema de fácil solución, habida cuenta de que en este caso la escritura arranca de la vida misma y puede confundirse con cualquier ejercicio de escritura coticliana, corriente y moliente. T'engo presente ahora un libro reciente de Gérard Genette, a quien tanto debemos ya, Rïction é diction (París, 1991), cuyos términos no contradicen la introducción en García Berrio de la literariedad como opeión inicial de un texto. Calilica (ienette esta condición inalugural, o la Poélica que en ella se apoya para sus definiciones, de uconstitutivil» (constimutive). Lo que hace que un escrito sea literario no es cuestión de evaluación estética. Lo principal es el presentarse o constituirse radicalmente como fieción o como poesía. «Si una epopeya, una tragedia, un soneto o una novela son obras literarias, no es en virtud de una evaluación estétical, por muy universal que sea, sino por una rasge de su naturaleza (par un mair de nentre). como la ficcionalidad o la forma poética. Si Britammicus es obra literaria, no es porque me gusta esta obra, ni siquiera porque le gusta a todo el mundo (lo cual (lucko), simo porque es una piera de teatro (unce piece de théatere)..." (p. 29). Las dos condiciones que constituyen la literariedad son la ficción desde la Pó́tica de Aristóteles y la forma poética, cue ejemplifica mejor cue rodo la poesía (en el sentido más pleno de la palabra, como en Paul Valéry y Roman Jakobson, que (ienctle denominal también dicrion).

Pero se tropieza con una dificultad, muy importante y tan antigua como los diálogos platónicos, la prosa no ficticia: historiografía, alutobiogratfía, ensalyo, ctc. Lal literariedad de talles escritos es algo que determina a posteriori una aproximación o un criterio que (ienette llama "condicional» (conditionnel). Si un texto historiográfico se nos aparece como literario, es básicamente porque hemos descubierto en él ciertas cualidades formales; y porque en consecuencia ha llegado a ser literario, se ha vuelto literatio. En qué consisten los rasgos y circunstancias que hacen que ello ocurra no queda muy claro, y es prudente asumir que son plurales; pero parece que tienden a coincidir con obscrvaciones a lo Jakobson como: "un texto es literario (y ya no solamente poético) para cuienes se hallan más attaídos por su forma que por su contenido, paral quienes por ejemplo aprecian su escritura (sca rédection) mientrals rechazan o descuidan su sentido» (p. 27).

Pienso que la pertinencia de los géneros, situados históricamente, puede mediar entre la Poélica constilutiva y la condicional. No basta una ve\% más con clestacar los cauces más generales de comunicación, como el (laamático y el poćlico, y calegorias tan valstas o lan opinalbles como la ficcionalidad, sin distinguirlos bien de los géneros literarios precisos cue cllos propiciaron. Presume Genette gue Britamnicus es constitutivamente literario porque es una pièce de théâtre. es clecir, porgue es una ficción, o sea, la ilusión y representación die unals cscenas imaginadas. Me parece que puede mirarse más exactamente, y con la misma radicalidad, como una tragedia, dotada de los compronisos temáticos y formales que por anuel entonces caracterizaban al género. Cierto gute en este calso la lieceionalidad es concepto asimismo constitutivo. y bastante más amplio. Fl (lescubrimiento del género, sin embargo, es csencial cuando nos aproximamos a diálogos, autobiografías, ensayos, máximas, carcurcìres, diarios, estampas costumbristas - y epístolas familiares. In tales ocasiones la historia de esals clases de escritura nos permite reconocer la literariedad como una circunstancia envolvente que no depende de respuestas afirmativals a preguntas como «jes esto una fieción?" o "jise encuentran cualidades formales"»». De no ser así tropezaríamos con dos dificultades. Resultaría, primero, que confundiríamos la decerminación de la literariedad con lat evaluación estética, muy a pesar nuestro y de Genette. L.o principal debería seguir siendo pensar "esto es literatura». ¿Y por qué no ha de ser ello posible en el caso, por cjemplo, de determinado ensayo 
de Ortega o de Camus? ¿No cabe acaso reconocer (jue ese texto particular es un ensalyo literario, auncue no nos guste?" () deberíamos, en segunclo lugar, volver hacia altás y elepender de la tradición de la Relórical, al lo Mme. de Sévigné, de la sufieiencia de escribir bien, de las cualidades de rédection: y así no poder deteminar claramente la literariedad de las Familier. res de Petrarca, por ejemplo, que comenté más arriba.

Haría falta todo un libro para recorrer paso a paso el itinerario de la epístola familiar desde los orígenes romanos hasta los humanistas del Renacimiento y aquellos autores italianos, españoles, lianceses e ingleses que lueron muy conscientes, hasta bien entraclo el siglo XVIII, de sus predecesores como modelos, de la teoría de la carta. o de ciertas obligaciones temáticas y formales; y para tomar en consideración también aquellas comunicaciones epistolares que pasaron a ser condicionalmente literarias, por decirlo con Genette, en la opinión de muchos lectores en ciertos momentos históricos. ¿Y la novela epistolar? Serál constitulivatmente literarlia, qué duda cabe, como obra de fieción; pero no sin ambigüedad, puesto cjue es harto arduo distinguir, sin información exterior al texto, decíamos antes, entre una calta ficticia y ora real; ni siempre tan lácil desemmascarar los usos de la ilusión de no-lïccionalidad como mero procedimiento literario (el manuscrito hallado en un baúl. etc.), a diferencia de su aparición en la vertiente imaginaria de cartas verdaderas $-y$ también de epístolas familiares.

\section{9}

Un éxito intemacional tan notable como el del Aretino, pero más duradero, premianá la publicación en 1669 por el editor Claude Barbin, en Parrís, de un libre anónimo titulado Le't-


d'ume religiéuse porrusgaise. logró producir mejor (pue ningún otro la ilusión epistolar de nofiecionalidad. Muy pronto se multiplicaron los rumores y las cábalas acerca de la iclenticlacl del oficial francés del que se había enamorado tan alpasionadamente la monja pertuguesia, quizás el Conde Chamilly, decían muchos, to cual sorprendió sobremancra a Saint-Simon, que le concontraba demasiado soso; y se conjeluró que el traductor podría ser el conde de Guilleragues, amigo de Racine y de Boileau, muy conocido en la Corte por su ingenio y atractivo, según por ejemplo Madame de Sévigné, que repite una de sus frases: "(juilleragues disait hier que Pellisson abusait de la permission qu'ont les hommes d'être laids» (5 de enero, 1674). Pero se pensó ante kdo que el autor era la monja misma, llamada Marianne en el texto, sencillamente, y más antelante. tras el supuesto hallazgo de un periodista, Boissonade, el año 1810, Marianne Akoforado; o Mariana Alcoforada, a consecuencia de las investigaciones de los estudiosos portugueses que no dejaron de interesarse por la cuestión.

La ilusión de autenticidad, con la que sin duda contara Barbin, se consiguió hasta al menos la ćpoca de Rilke, que traduce las cartas en 1913, convencido de que eran, según êl, de Martianna Alcoforado. No conozco calso semejante de narración anónima cuyo protigonisla pasara siglo trats siglo por ser el autor del libro. Fes la superchería en que descansó inicialmente el Lazcrillo de Tormes. explica Francisco Rico, y no digo ahora que éste no tenga ladzón; sólo (jue los lectores no pudieron creérselo durante mucho más de medio siglo, puesto que desde principios del XVII todos se preguntan quién sería el verdadero autor. líra sin duda más difícil de admitir el talento de escritor o siquieral la alfabetización de un mozueto de ciego, errabundo por calles y descampados descle la primera infancia, que el de una monja de buena familia. Volviendo a éstia, el único escritor de renombre que no cayó en la trampa, durante doscientos cincuenta años, fue Jean-Jacques Roussealu, que afirmó en un momento de 


\section{(I.AUDIO GUIL.IEN}

intensal mosoginia de su loflle a d Alembert que las mujeres son incapaces de escribir con genio y pasión. exceptuando a Sato, y que por ello apostaba todo en el mundo que el atutor

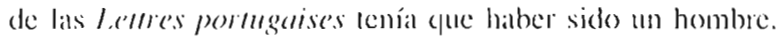

Llevaba la razón Rousseatu, efectivamente, aumpac fuela con argumentos vulgalles. Frederick (: Grén publicó en un artículo de 1926 el manuscrito original del Privilegio concedi(o) por el Rey a claude Barbin el 26 de octubre de 1668 . con lo cual queda probado yue el autor era (inilleragnes. Y un crílico genial, leo Spilzer, mostró en un ensayo de 1953 (jue las cinco lertress componen una obra de ante literaria perfectamente equilibrada, y comparable, según él, a los cinco actos de un drama de Racine" ".

la premisa mayor (que hizo posible este éxito excepecional de la ilusión de no-líccionalidad ela que la expresión totalmente convincente y eréble de un amor tan apasionado (e)mo el ale la monja portugnesa no podía simo ser espontánea, natural y verídical. La estética que iba unida a lal premisa cra la clesconliamea de la imaginación poétical, lan callacterística del lílimo tercio del siglo XVII en firancia (es por ejemplo cuando escritores como Courtil\% de Sandras lanyan la boga de las falsals Mémoiress) y buena parte del XVIII en Europa. Se manilestaba por medio de conocidas técnicas retóricias la esperanza de que la literatura imitara la vida, o la "maturalezal». con un minnmo de habilidad y artificio; y. charo. entre estas récnicas descollaba el uso de las cartas, tan próximas a la vida coticliana y a la experiencia del lector. Lil cultivo creciente al mismo tiempo de la epóstola lamiliar confimaba este desalpego o indiferencia por parte de muchos ante no sólo la literariedad declarada simo ante la poeticidad; o al menos ante la expresión de la pasión crótica en poesía tam importante y decisiva para la literatura couropea desde la Fiad Media hisela el Barroco.

Guilleragues, que llegó a ser embajador (le liancia en Comstantinopla, era una persona de expuisita educación y elegancia, según prueba su propia correspondencia' '. La composición de las carlas pontuguesas puclo haberse iniciade como un juego de sociedad, en que se

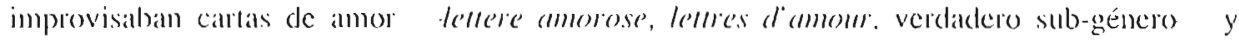
se llataban questions d'amom Pero ningún escritor percibió más inteligentenente las posibilidades de la ilusión epistolar. Afirma Julia Kristeva que la experiencia del amor conjuga inextricablemente lo simbólico, lo imaginario y lo real’. Ll hallazgo de (iuilleragues consistió en unir radicalmente la calidad imaginaria de la emoción anorosa a la de la escrimra epistolar. Marianne es una mujer abandonada, que escribe uma lleroida, en la lradición ovidiana. dirigicla a su amante lejano. Al principoio ella disfruta sufriendo: «je vous ai destiné ma vie aussilôt que je vous ai vu, el je sens quelque plasisir à vous la sacritier» (carta 1). Fl que fie su amante no responde a ninguna de las carlas. Y Marianne se pueda solat con sus sentimientos. sus memorias y su pluma. I a concentración extrema. la brevitas, del lenguaje

todo rapide\%, encamto, frescura- revela claramente pue el desamrollo de las emociones de la probagonista es inclivisible de la carrera autónoma de la palabra escrita.

la pasión de Marianne va aumentando conforme sigue escribiendo; y las palabras se

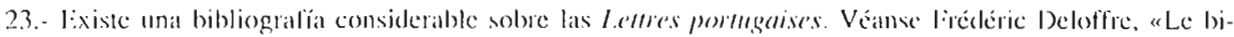

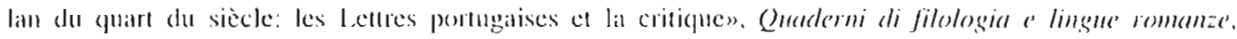
1984, 121-164: y su edición del texto para (iallimard. Col. "Foliom. París, 1990), donde se resume cl es-

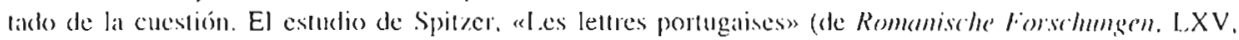

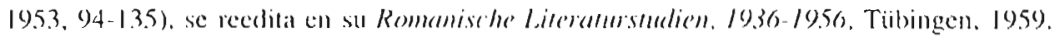

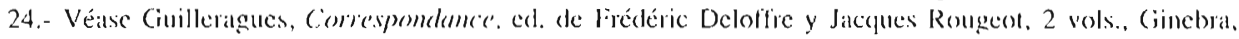
"Textes l,ittéraires Français». 1976.

25.- Véasce J. Kristeva, Histoire's d'amomr, París. 1983, p. 14. 
multiplican e intersifican con el ritmo de kos sentimientos. Así, ke es difícil terminar la carta terceral: "Adieu, ma passion alugmente a chatpue moment. Ah! que j'ai de choses à vous (lire». Pronto quedia claro, para el lector y para ella, que este anor desmesurado existe y florece en un espacio verbal, en el lenguaje de una tierra de nadie epistolar, o mejor. de una tierra de mujer absolutamente sola --espacio o tierra (fue es su construcción. su propiedad y sul secreto. "Ah! jen meurs de honte: mon désespoir n'est donc que dans mes letrres"? (carta 3). Abanclonadlass a sí mismals, a su verbalismo, su autar(uía, su solipsismo, como dice Spitzer, las emociones de Marianne no pueden sino marchitarse y morir. De tal sucrte Guilleragues logra aproximarse a la parodia sin incurrir en ella pues ihasta dónde no es lícito el desviríos en el amor? --, o a un grado de iromía que no sólo descubriese la liagiliclad de la fieción vivida por Marianne sino la del propio autor.

Fra difícil ir más lejos o desenvolver con más lino la ilusión crótico-epistolar. Pero aqué es un ilusión verdaclera, si algo es"? ¿No basta con (jue nos (lemos por convencidos, entre lass ficciones del anor, las del lenguaje y las de la epistolaridadl? De hecho el espejismo bascinó a los lectores de las leetres pormugaises y de sus immumerables sucesores durante el siglo XVIII. Las posibilidades de desarrollo cuantitativo y formal - natuatológicamente- cran muchas. Todos saben que después de Crébillon y Richardson y hasta el final del sigglo, hasta Rétif de la Bretonne y el margués de Sade y Ugo Foscolo, las novelas epistolares. malas o buenass o medianlas, fueron numerosísimas. Dutante sólo tres años, entre 1785 y 1788 . se pu-

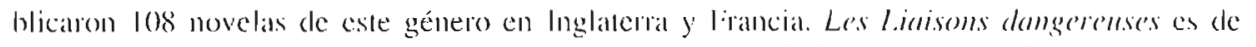
1782. Werther, de 1774. De 1780 a 1800 la tercera parte de las novelas escribals cn Alemanial fucron epistolares ze. También lo era la primera novela original que se escribici en Norteamérica. The Power of Symparlyy, de William Hill Brown. publicadia en Boston el año 1789. Pero la boga no pucte (lurar mucho más. I:I género decayó abruptanente. víctima de la Revolución francesa - de sus propias convenciones, que cesaron de parecer naturales y espontáncals, o de lo cue los formalistas rusos denominarían falliga y automatización.

Durante las primeras décadals del siglo XIX. con la Restauración en Francia de la monarguía y de las instituciones católicas. hubo intentes de cultivar la novela epistolar. Quien estuvo de acuerdo con estals recuperaciones fue desde luego Balzace: y acalso la más auléntical y viva de estas narraciones fuera su Mémoires de deur jemes mariées (1842). pese a lo evidente y voluntarioso de la iedeología. Ahora bien, lo que sí perdura es la parte de ilusión epistolar (jue la composición de tantas cartas sigue conteniendo, por mucho gue la epsistolat fatmiliar hayal dejade en nuestra época de luncionar como modelo. continuidiad og género.

F:1 28 de febrero de 18.32 una distinguida señola polaca echa un sobre en un buzón de Odessal: es una carta de admiradora, una fan letter. dirigida a Balzac. la autora es tive Hanskat, de soltera llamada la condesa Rzewuska. La carta tarda en llegar. La primera de las respuestas del escritor, en malyo, consiente inmediatamente el vacto del ensueño epistolan; pero no sin (jue él se dé perfecta cuenta de sul conteniclo novelesco:

Si vous diagne\% excuser la folic d'un cur jeune. el d'une imagination toute vicrge, je vous avoucrai que vous avez été pour moi l'objet des plus doux rêves. Fin dépit dic mes travaux. je me suis surpris plus d'une fois, chevauchant a travers Ies espaces el voltigeant dans la contrée inconnuc où vous, inconnue, habitien seule de votre race...

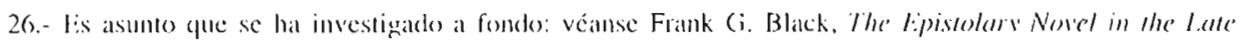

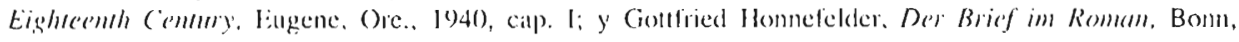
1975. p. 106. 


\title{
CLAUIT) (iUM.IIEN
}

Cé fun un épisode cou romanesque. mais qui osera blâmer le romanesque; il n'y a que les âmes liroides qui ne conçoivent pas tout ce qu'il y a de valste dans les émotions auxquelles l'incomnu donne carrière libre. Je me suis done laissé doucement aller ì mes rêveries; et j'en ai lait de ravissantes ${ }^{27}$.

La liberación de las normass de la lengua y la forma literarias liberación muy relativit. o mejor dicho, dominadora y consciente de sí misma ha teniclo, según venimos viendo, consecuencials sorprendentes. (Como uno de mestros escritores de más talento, Francisco Umbral, dijo una ve\%: "pero qué bien se escribe cuando no se pretende escribir bien». El secreto del éxito era, al partecer, el ejercicio de la libertad. Isscribir lelizmente, quiero decir, acerladamente, como muestran los géneros (pue acabo de recordar, era escribir con feliz disposición de ánimo, independientemente del tema, del interés práctico ý de la obligación de escribir bien. Mecliante esla liberación inciertil, precartia, creadora- de la literatura, sí, era posible disfrutar del placer de la escritura. Cieerón le diee más de una ver. a Atico: no tengo nalda que decirle (ad Allicum 9, 10; 12,53); y, sin embargo, acto seguido le escribe. (Otro lanto han pensado y hecho muchos de sus sucesores: lo cue se dice es menos importante que la voluntad de decir. Actitud, éstil, que llevaría muchats veces a lo que el Dr. Johnson llamaba "the decoration of insignificance»"2. Pero también podía y pude significar la entrega más verdadera a la comunicación de la amistad y del afecto. Termino con un ejemplo contento. yo lambién. con dejarle la última palabra a John Donne, cuando escribe a Mrs. Bridget White:

\begin{abstract}
Madiam,
I could make some guess whether souls that go to heaven retain any memory of us that staly behind, if I knew whether you ever thought of us, since you enjoyed your heaven, which is your self, at home. Your going away has made London a dead cartcalss. A Term and a Count do a litte spice and embalm it, and keep it from putrelaction, but the soul went away in you: and I think the only reason why the plague is somewhal slackened is beciluse the place is dead alleady, and nobody left worth the killing. Wheresoever you are, there is London enough: and it is a diminishing of you to saly so, since you are more than the rest of the world. When you have a desire (1) work a miracle, you will return hither, and raise the place from the dead, and the dead that are in it: of which I am one. but that a hope that I have a room in your favour keeps me allive, which you shall abundantly confirm to me if by one letter you tell me that you have received my six; for now my letters are grown to that bulk that I may divide them like Amadis de Gaule's book, and tell you that this is the first letter of the Second Pialt of the litst Book.
\end{abstract}

Your humblest and affectionate servant.

J.门. $\because$

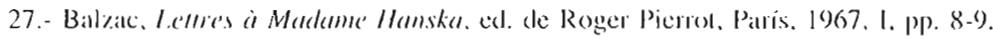

28. - S. Johnson, The R(min)ler, n." 1.52.

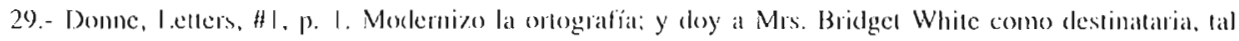
como aparece en la edición póstuma publicarla en 16.51 por el hijo (ke I)onne, que al parecer manipuló las callan con anreglo a sus prepios intereses; véase liness Sullivan, eThe Problem of Text in lamilial

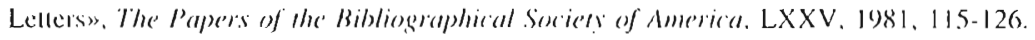

